\title{
Stable Fuzzy PD Control with Parallel Sliding Mode Compensation with Application to Rigid Manipulator
}

\author{
Farzin Piltan \\ Industrial Electrical and Electronic Engineering SanatkadeheSabze Pasargad. CO (S.S.P. Co), NO:16 , PO.Code 71347- \\ 66773, Fourth floor, Dena Apr, Seven Tir Ave, Shiraz, Iran \\ E-mail: SSP.ROBOTIC@gmail.com
}

Mohammad A. Bairami

Industrial Electrical and Electronic Engineering SanatkadeheSabze Pasargad. CO (S.S.P. Co), NO:16 , PO.Code $71347-$ 66773, Fourth floor, Dena Apr, Seven Tir Ave, Shiraz, Iran E-mail:SSP.ROBOTIC@yahoo.com

Farid Aghayari

Industrial Electrical and Electronic Engineering SanatkadeheSabze Pasargad. CO (S.S.P. Co), NO:16 , PO.Code 7134766773, Fourth floor, Dena Apr, Seven Tir Ave, Shiraz, Iran

E-mail:SSP.ROBOTIC@yahoo.com

\author{
Mohammad Reza Rashidian \\ Industrial Electrical and Electronic Engineering SanatkadeheSabze Pasargad. CO (S.S.P. Co), NO:16 , PO.Code 71347- \\ 66773, Fourth floor, Dena Apr, Seven Tir Ave, Shiraz, Iran \\ E-mail:SSP.ROBOTIC@yahoo.com
}

\begin{abstract}
Both fuzzy logic and sliding mode can compensate the steady-state error of proportionalderivative (PD) control. This paper presents parallel sliding mode compensations for fuzzy PD controllers. The asymptotic stability of fuzzy PD control with firstorder sliding mode compensation in the parallel structure is proven. For the parallel structure, the finite time convergence with a super-twisting second-order sliding-mode is guaranteed.
\end{abstract}

Index Terms - Fuzzy Logic Control, Sliding Mode Control, PD Control, Parallel Sliding Mode Compensation

\section{Introduction}

Robot manipulator is a $N$ Degrees Of Freedom (DOF) serial or parallel links. In serial links robot manipulator the axes of first three joints are known as major axes, these axes show the position of end-effector and design a position controller is based on first three axes. One of the significant challenges in control algorithms is a linear behavior controller design for nonlinear systems (e.g., robot manipulator). Some of robot manipulators which work in industrial processes are controlled by linear PD, proportional-integral-derivative (PID) controllers, but the design of linear controller for robot manipulators is extremely difficult because they are hardly nonlinear and uncertain $[1-2,6]$. To reduce the above challenges, the nonlinear robust controller is used to compens ate the linear control of robot manipulator.

Controller is a device which can sense information from linear or nonlinear system (e.g., robot manipulator) to improve the systems performance [3]. The main targets in designing control systems are stability, good disturbance rejection, and small tracking error[5]. Several industrial robot manipulators are controlled by linear methodologies (e.g., Proportional-Derivative (PD) controller, Proportional- Integral (PI) controller or Proportional- Integral-Derivative (PID) controller), but when robot manipulator works with various payloads and have uncertainty in dynamic models this technique has limitations. From the control point of view, uncertainty is divided into two main groups: uncertainty in unstructured inputs (e.g., noise, disturbance) and uncertainty in structure dynamics (e.g., payload, parameter variations). In some applications robot manipulators are used in an unknown and unstructured environment, therefore strong mathematical tools used in new control methodologies to design fuzzy PD controller based on sliding mode compensation to have an acceptable performance (e.g., minimum error, good trajectory, disturbance rejection) [4-5]. 
Fuzzy-logic aims to provide an approximate but effective means of describing the behavior of systems that are not easy to describe precisely, and which are complex or ill-defined [7-11,22]. It is based on the assumption that, in contrast to Boolean logic, a statement can be partially true (or false) [12-21, 23-33]. For example, the expression (I live near SSP.Co) where the fuzzy value (near) applied to the fuzzy variable (distance), in addition to being imprecise, is subject to interpretation. The essence of fuzzy control is to build a model of human expert who is capable of controlling the plant without thinking in terms of its mathe matical model. As opposed to conventional control approaches where the focus is on constructing a controller described by differential equations, in fuzzy control the focus is on gaining an intuitive understanding (heuristic data) of how to best control the process [28], and then load this data into the control system [34-35].

Sliding mode control (SMC) is obtained by means of injecting a nonlinear discontinuous term. This discontinuous term is the one which enables the system to reject disturbances and also some classes of mis matches between the actual system and the model used for design

[12, 36-44]. These standard SMCs are robust with respect to internal and external perturbations, but they are restricted to the case in which the output relative degree is one. Besides, the high frequency switching that produces the sliding mode may cause chattering effect. The tracking error of SMC converges to zero if its gain is bigger than the upper bound of the unknown nonlinear function. Boundary layer SMC can assure no chattering happens when tracking error is less than ; but the tracking error converges to $\varepsilon$; it is not asymptotically stable [13]. A new generation of SMC using second-order sliding-mode has been recently developed by [15] and [16]. This higher order SMC preserves the features of the first order SMC and improves it in eliminating the chattering and fast convergence [45-53].

Normal combinations of PD control with fuzzy logic (PD+FL) and sliding mode (PD+SMC) are to apply these three controllers at the same time [17], while FLC compensates the control error, SMC reduces the remain error of fuzzy PD such that the final tracking error is asymptotically stable [18]. The chattering is eliminate, because PD+SMC and PD+FL work parallel. In this paper, the asymptotic stability of PD control with parallel fuzzy $\log$ ic and the first-order sliding mode compensation is proposed (PD+SMC+FL). The fuzzy PD is used to approximate the nonlinear plant. A dead one algorith $\mathrm{m}$ is applied for the fuzzy PD control. After the regulation error enter converges to the dead-zone, a super-twisting second-order sliding-mode is used to guarantee finite time convergence of the whole control (PD+FL+SMC). By means of a Lyapunov approach, we prove that this type of control can ensure finite time convergence and less chattering than SMC and SMC+FL [33-53].
This paper is organized as follows; second part focuses on the modeling dynamic formulation based on Lagrange methodology, fuzzy logic methodology and sliding mode controller to have a robust control. Third part is focused on the methodology which can be used to reduce the error, increase the performance quality and increase the robustness and stability. Simulation result and discussion is illustrated in forth part which based on trajectory following and disturbance rejection. The last part focuses on the conclusion and compare between this method and the other ones.

\section{Theory}

\subsection{Robot Manipulator's Dynamic:}

Dynamic modeling of robot manipulators is used to describe the behavior of robot manipulator such as linear or nonlinear dynamic behavior, design of model based controller such as pure sliding mode controller and pure computed torque controller which design these controller are based on nonlinear dynamic equations, and for simulation. The dynamic modeling describes the relationship between joint motion, velocity, and accelerations to force/torque or current/voltage and also it can be used to describe the particular dynamic effects (e.g., inertia, coriolios, centrifugal, and the other parameters) to behavior of system[1]. The Unimation PUMA 560 serially links robot manipulator was used as a basis, because this robot manipulator is widely used in industry and academic. It has a nonlinear and uncertain dynamic parameters serial link 6 degrees of freedom (DOF) robot manipulator. The equation of an $n-D O F$ robot manipulator governed by the following equation $[1,4,15-29,41-53]$ :

$$
M(q) \ddot{q}+N(q, \dot{q})=\tau
$$

Where $\tau$ is actuation torque, $\mathrm{M}(\mathrm{q})$ is a symmetric and positive define inertia matrix, $N(q, \dot{q})$ is the vector of nonlinearity term. This robot manipulator dynamic equation can also be written in a following form [1-29]:

$$
\tau=M(q) \ddot{q}+B(q)[\dot{q} \dot{q}]+C(q)[\dot{q}]^{2}+G(q)
$$

Where $B(q)$ is the matrix of coriolios torques, $C(q)$ is the matrix of centrifugal torques, and $\mathrm{G}(\mathrm{q})$ is the vector of gravity force. The dynamic terms in equation (2) are only manipulator position. This is a decoupled system with simple second order linear differential dynamics. In other words, the component $\ddot{q}$ influences, with a double integrator relationship, only the joint variable $q_{i}$, independently of the motion of the other joints. Therefore, the angular acceleration is found as to be $[3$, 41-53]:

$$
\ddot{q}=M^{-1}(q) .\{\tau-N(q, \dot{q})\}
$$

This technique is very attractive from a control point of view. 


\subsection{Model free Control Technique}

The model-free control strategy, is based on the assumption that the joints of the manipulators are all independent and the system can be decoupled into a group of single-axis control systems [18-23]. Therefore, the kinematic control method always results in a group of individual controllers, each for an active joint of the manipulator. With the independent joint assumption, no a priori knowledge of robot manipulator dynamics is needed in the kinematic controller design, so the complex computation of its dynamics can be avoided and the controller design can be greatly simplified. This is suitable for real-time control applications when powerful processors, which can execute complex algorith ms rapidly, are not accessible. However, since joints coupling is neglected, control performance degrades as operating speed increases and a manipulator controlled in this way is only appropriate for relatively slow motion [44, 46]. The fast motion requirement results in even higher dynamic coupling between the various robot joints, which cannot be compensated for by a standard robot controller such as PD [50, 51-60], and hence model-based control becomes the alternative. Based on above discussion;

$$
\begin{aligned}
& e_{1}(t)=\theta_{\text {desired }}(t)-\theta_{\text {actual }}(t) \\
& \tau_{\alpha}=K_{p_{a}} e_{1}+K_{V_{a}} \dot{e_{1}}
\end{aligned}
$$

\subsection{Sliding Mode Controller}

Consider a nonlinear single input dynamic system is defined by [6]:

$$
x^{(n)}=f(\vec{x})+b(\vec{x}) u
$$

Where $\mathrm{u}$ is the vector of control input, $\boldsymbol{x}^{(\boldsymbol{n})}$ is the $\boldsymbol{n}^{\text {th }}$ derivation of $\boldsymbol{x}, \boldsymbol{x}=\left[x, \dot{x}, \ddot{x}, \ldots, x^{(n-1)}\right]^{T}$ is the state vector, $\boldsymbol{f}(\boldsymbol{x})$ is unknown or uncertainty, and $\boldsymbol{b}(\boldsymbol{x})$ is of known sign function. The main goal to design this controller is train to the desired state; $\boldsymbol{x}_{\boldsymbol{d}}=$ $\left[\boldsymbol{x}_{d}, \dot{\boldsymbol{x}}_{d}, \ddot{\boldsymbol{x}}_{d}, \ldots, \boldsymbol{x}_{d}{ }^{(\boldsymbol{n}-1)}\right]^{\boldsymbol{T}}$, and trucking error vector is defined by [6]:

$$
\tilde{x}=x-x_{d}=\left[\widetilde{x}, \ldots, \widetilde{x}^{(n-1)}\right]^{T}
$$

A time-varying sliding surface $\boldsymbol{s}(\boldsymbol{x}, \boldsymbol{t})$ in the state space $\boldsymbol{R}^{\boldsymbol{n}}$ is given by [6]:

$$
s(x, t)=\left(\frac{d}{d t}+\lambda\right)^{n-1} \tilde{x}=0
$$

where $\lambda$ is the positive constant. To further penalize tracking error, integral part can be used in sliding surface part as follows [6]:

$$
s(x, t)=\left(\frac{d}{d t}+\lambda\right)^{n-1}\left(\int_{0}^{t} \tilde{x} d t\right)=0
$$

The main target in this methodology is kept the sliding surface slope $\boldsymbol{s}(\boldsymbol{x}, \boldsymbol{t})$ near to the zero. Therefore, one of the common strategies is to find input $\boldsymbol{U}$ outside of $\boldsymbol{s}(\boldsymbol{x}, \boldsymbol{t})$ [6].

$$
\frac{1}{2} \frac{d}{d t} s^{2}(x, t) \leq-\zeta|s(x, t)|
$$

where $\zeta$ is positive constant.

$$
\text { If } \mathbf{S}(\mathbf{0})>\mathbf{0} \rightarrow \frac{\mathrm{d}}{\mathrm{dt}} \mathbf{S}(\mathbf{t}) \leq-\zeta
$$

To eliminate the derivative term, it is used an integral term from $\mathrm{t}=0$ to $\mathrm{t}=\boldsymbol{t}_{\text {reach }}$

$$
\begin{aligned}
\int_{t=0}^{t=t_{\text {reach }}} \frac{d}{d t} S(t) & \leq-\int_{t=0}^{t=t_{\text {reach }}} \eta \\
& \rightarrow S\left(t_{\text {reach }}\right)-S(0) \\
& \leq-\zeta\left(t_{\text {reach }}-0\right)
\end{aligned}
$$

Where $t_{\text {reach }}$ is the time that trajectories reach to the sliding surface so, suppose $\mathrm{S}\left(t_{\text {reach }}=0\right)$ defined as;

$$
0-S(0) \leq-\eta\left(t_{\text {reach }}\right) \rightarrow t_{\text {reach }} \leq \frac{S(0)}{\zeta}
$$

and

$$
\text { if } \begin{aligned}
S(0)<0 \rightarrow 0 & -S(0) \leq-\eta\left(t_{\text {reach }}\right) \\
& \rightarrow S(0) \leq-\zeta\left(t_{\text {reach }}\right) \\
& \rightarrow t_{\text {reach }} \leq \frac{|\boldsymbol{S}(\mathbf{0})|}{\eta}
\end{aligned}
$$

Equation (14) guarantees time to reach the sliding surface is smaller than $\frac{|S(\mathbf{0})|}{\zeta}$ since the trajectories are outside of $S(t)$.

$$
\text { if } S_{t_{\text {reach }}}=S(0) \rightarrow \operatorname{error}\left(x-x_{d}\right)=0
$$

suppose $S$ is defined as

$$
\begin{aligned}
s(x, t)=\left(\frac{d}{d t}+\lambda\right) & \tilde{x} \\
= & \left(\dot{\mathbf{x}}-\dot{\mathbf{x}}_{\mathbf{d}}\right) \\
& +\lambda\left(\mathbf{x}-\mathbf{x}_{\mathbf{d}}\right)
\end{aligned}
$$

The derivation of $\mathrm{S}$, namely, $\dot{S}$ can be calculated as the following;

$$
\dot{S}=\left(\ddot{\mathbf{x}}-\ddot{\mathbf{x}}_{\mathbf{d}}\right)+\lambda\left(\dot{\mathbf{x}}-\dot{\mathbf{x}}_{\mathbf{d}}\right)
$$

suppose the second ordersystemis defined as;

$$
\begin{aligned}
\ddot{x}=f+u \rightarrow \dot{S} & =f+U-\ddot{x}_{d} \\
& +\lambda\left(\dot{\mathbf{x}}-\dot{\mathbf{x}}_{\mathrm{d}}\right)
\end{aligned}
$$


Where $\boldsymbol{f}$ is the dynamic uncertain, and also since $S=0$ and $\dot{S}=0$, to have the best approximation, $\widehat{\boldsymbol{U}}$ is defined as

$$
\widehat{U}=-\widehat{f}+\ddot{x}_{d}-\lambda\left(\dot{\mathbf{x}}-\dot{\mathbf{x}}_{\mathbf{d}}\right)
$$

A simple solution to get the sliding condition when the dynamic parameters have uncertainty is the switching control law [52-53]:

$$
U_{d i s}=\widehat{U}-K(\vec{x}, t) \cdot \operatorname{sgn}(s)
$$

where the switching function $\mathbf{s g n}(\mathbf{S})$ is defined as $[1,6]$

$$
\operatorname{sgn}(s)= \begin{cases}1 & s>0 \\ -1 & s<0 \\ 0 & s=0\end{cases}
$$

and the $\boldsymbol{K}(\overrightarrow{\boldsymbol{x}}, \boldsymbol{t})$ is the positive constant. Suppose by (10) the following equation can be written as,

$$
\begin{aligned}
\frac{1}{2} \frac{d}{d t} s^{2}(x, t)=\dot{S} & \cdot S \\
= & {[f-\widehat{f}-K \operatorname{sgn}(s)] } \\
& \cdot S \\
= & (f-\hat{f}) \cdot S-K|S|
\end{aligned}
$$

and if the equation (14) instead of (13) the sliding surface can be calculated as

$$
\begin{aligned}
s(x, t)=\left(\frac{d}{d t}+\lambda\right)^{2} & \left(\int_{0}^{t} \tilde{x} d t\right) \\
& =\left(\dot{\mathbf{x}}-\dot{\mathbf{x}}_{\mathrm{d}}\right) \\
& +2 \lambda\left(\dot{\mathbf{x}}_{\mathrm{d}}\right) \\
& -\lambda^{2}\left(\mathbf{x}-\mathbf{x}_{\mathrm{d}}\right)
\end{aligned}
$$

in this method the approximation of $\boldsymbol{U}$ is computed as [6]

$$
\begin{aligned}
\widehat{U}=-\widehat{f}+\ddot{x}_{d}- & 2 \lambda\left(\dot{\mathbf{x}}-\dot{\mathbf{x}}_{\mathbf{d}}\right) \\
& +\lambda^{2}\left(\mathbf{x}-\mathbf{x}_{\mathbf{d}}\right)
\end{aligned}
$$

Based on above discussion, the sliding mode control law for a multi degrees of freedom robot manipulator is written as $[1,6]$ :

$$
\tau=\tau_{e q}+\tau_{d i s}
$$

Where, the model-based component $\boldsymbol{\tau}_{\boldsymbol{e q}}$ is the nominal dynamics of systems calculated as follows [1]:

$$
\tau_{e q}=\left[M^{-1}(B+C+G)+\dot{S}\right] M
$$

and $\boldsymbol{\tau}_{\text {dis }}$ is computed as [1];

$$
\tau_{d i s}=K \cdot \operatorname{sgn}(S)
$$

By (27) and (26) the sliding mode control of robot manipulator is calculated as;

$$
\begin{gathered}
\tau=\left[M^{-1}(B+C+G)+\dot{S}\right] M+K \\
\cdot \operatorname{sgn}(S)
\end{gathered}
$$

where $S=\lambda e+\dot{e}$ in PD-SMC and $S=\lambda e+\dot{e}+$ $\left(\frac{\lambda}{2}\right)^{2} \sum e$ in PID-SMC.

\subsection{Proof of Stability}

The lyapunov formulation can be written as follows,

$$
V=\frac{1}{2} S^{T} . M . S
$$

the derivation of $V$ can be determined as,

$$
\dot{V}=\frac{1}{2} S^{T} \cdot \dot{M} \cdot S+S^{T} M \dot{S}
$$

the dynamic equation of robot manipulator can be written based on the sliding surface as

$$
M \dot{S}=-V S+M \dot{S}+B+C+G
$$

it is assumed that

$$
S^{T}(\dot{M}-2 B+C+G) S=0
$$

by substituting (31) in (30)

$$
\begin{array}{rl}
\dot{V}=\frac{1}{2} S^{T} \dot{M} S-S^{T} & B+C S \\
& +S^{T}(M \dot{S}+B+C S \\
& +G) \\
& =S^{T}(M \dot{S}+B+C S \\
& +G)
\end{array}
$$

suppose the controlinput is written as follows

$$
\begin{aligned}
\widehat{U}=U_{\text {Nonltnear }}+ & \widehat{U_{d \iota s}} \\
& =\left[\overline{M^{-1}}(B+C+G)\right. \\
& +\dot{S}] \widehat{M}+K \cdot \operatorname{sgn}(S) \\
& +B+C S+G
\end{aligned}
$$

by replacing the equation (34) in (29)

$$
\begin{aligned}
\dot{V}=S^{T}(M \dot{S}+B & +C+G-\widehat{M} \dot{S} \\
& -\widehat{B+C} S+G \\
& -K s g n(S) \\
& =S^{T}(\widetilde{M} \dot{S}+\widetilde{B+C S} \\
& +G-K \operatorname{sgn}(S))
\end{aligned}
$$

and

$$
\begin{aligned}
|\widetilde{M} \dot{S}+\widetilde{B+C} S+G| & \leq|\widetilde{M} \dot{S}|+|\widetilde{B+C} S+G|
\end{aligned}
$$

the Lemma equation in robot arm system can be written as follows 


$$
\begin{gathered}
K_{u}=[|\widetilde{M} \dot{S}|+|B+C S+G|+\eta]_{i}, i \\
=1,2,3,4, \ldots
\end{gathered}
$$

and finally;

$$
\dot{V} \leq-\sum_{i=1}^{n} \eta_{i}\left|S_{i}\right|
$$

\subsection{Fuzzy Logic Methodology}

Based on foundation of fuzzy logic methodology; fuzzy $\log$ ic controller has played important rule to design nonlinear controller for nonlinear and uncertain systems [53]. However the application area for fuzzy control is really wide, the basic form for all command types of controllers consists of;

Input fuzzification (binary-to-fuzzy $[\mathrm{B} / \mathrm{F}]$ conversion)

Fuzzy rule base (knowledge base), Inference engine and Output defuzzification (fuzzy-to-binary [F/B] conversion). Figure 1 shows the fuzzy controller part.

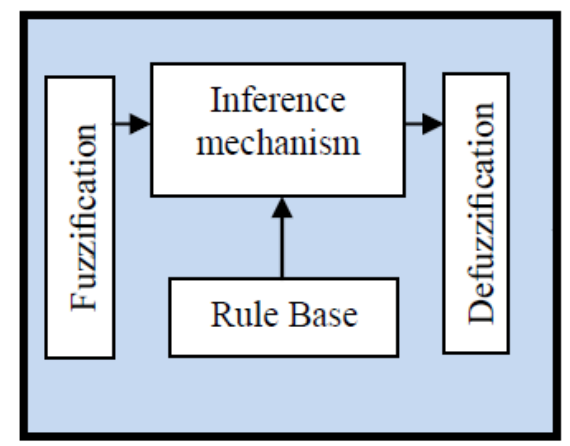

Fig. 1: Fuzzy Controller Part

The fuzzy inference engine offers a mechanism for transferring the rule base in fuzzy set which it is divided into two most important methods, namely, Mamdani method and Sugeno method. Mamdani method is one of the common fuzzy inference systems and he designed one of the first fuzzy controllers to control of system engine. Mamdani's fuzzy inference system is divided into four major steps: fuzzification, rule evaluation, aggregation of the rule outputs and defuzzification. Michio Sugeno use a singleton as a membership function of the rule consequent part. The following definition shows the Mamdani and Sugeno fuzzy rule base [22-33]

\section{if $x$ is $A$ and $y$ is $B$ then $z$ is $C$ 'mamda$$
\text { if } x \text { is } A \text { and } y \text { is } B \text { then } z \text { is } f(x, y) \text { 'sug }
$$

When $x$ and $y$ have crisp values fuzzification calculates the membership degrees for antecedent part. Rule evaluation focuses on fuzzy operation $(A N D / O R)$ in the antecedent of the fuzzy rules. The aggregation is used to calculate the output fuzzy set and several methodologies can be used in fuzzy logic controller aggregation, namely, Max-Min aggregation, Sum-Min aggregation, Max-bounded product, Max-drastic product, Max-bounded sum, Max-algebraic sum and Min-max. Defuzzification is the last step in the fuzzy inference system which it is used to transform fuzzy set to crisp set. Consequently defuzzification's input is the aggregate output and the defuzzification's output is a crisp number. Centre of gravity method (COG) and Centre of area method $(C O A)$ are two most common defuzzification methods.

\section{Methodol ogy}

Based on the dynamic formulation of robot manipulator, (3), and the industrial PD law (5) in this paper we discuss about regulation problem, the desired position is constant, i.e., $\dot{q}_{d}=0$. In most robot manipulator control, desired joint positions are generated by the trajectory planning. The objective of robot control is to design the input torque in (1) such that the tracking error

$$
e=q_{d}-q_{a}
$$

When the dynamic parameters of robot formulation known, the PD control formulation (11) shoud include a compensatoras

$$
\tau=-k_{p} e-k_{d} e+(G+F)
$$

Where $G$ is gravity and $F$ is appositive definite diagonal matrix friction term (coulomb friction).

If we use a Lyapunov function candidate as

$$
\begin{aligned}
& V_{p d}=\frac{1}{2} \dot{q}^{T} M \dot{q}+\frac{1}{2} e^{T} k_{p} e \\
& \dot{V}_{p d}=-\dot{q}^{T} k_{d} \dot{q} \leq 0
\end{aligned}
$$

It is easy to known $\dot{q}=0$ and $e=0$ are only initial conditions in $\Omega=\{[\dot{q}, e]: \dot{V}=0\}$, for which $[\dot{q}, e] \in \Omega$ for al $1 t \leq 0$. By the LaSalle's invariance principle, $e \rightarrow 0$ and $\dot{e} \rightarrow 0$. When G and $\mathrm{F}$ in (11) are unknown, a fuzzy logic can be used to approximate them as

$$
f(x)=\sum_{l=1}^{M} \theta^{l} \mathcal{E}^{l}(x)=\theta^{T} \mathcal{E}(x)
$$

Where

$\theta=\left(\theta^{1}, \ldots, \theta^{M}\right)^{T}, \mathcal{E}(x)=$ $\left(\mathcal{E}^{1}(x), \ldots, \mathcal{E}^{M}(x)\right)^{T}$, and $\mathcal{E}^{l}(x)=$ $: \prod_{i=1}^{n} \frac{\mu_{A_{i}^{l}}\left(x_{i}\right)}{} \sum_{l=1}^{M}\left(\prod_{i=1}^{n} \mu_{A_{i}^{l}}\left(x_{i}\right)\right) . \quad \theta^{1}, \ldots, \theta^{M} \quad$ are adjustable parameters in (44). $\mu_{A_{1}^{1}}\left(x_{1}\right), \ldots, \mu_{A_{n}^{m}}\left(x_{n}\right)$ are given membership functions whose parameters will not change over time. 
The second type of fuzzy systems is given by

$$
f(x)=\frac{\sum_{l=1}^{M} \theta^{l}\left[\prod_{i=1}^{n} \exp \left(-\left(\frac{x_{i}-\alpha_{i}^{l}}{\delta_{i}^{l}}\right)^{2}\right)\right]}{\sum_{l=1}^{M}\left[\prod_{i=1}^{n} \exp \left(-\left(\frac{x_{i}-\alpha_{i}^{l}}{\delta_{i}^{l}}\right)^{2}\right)\right]}
$$

Where $\theta^{l}, \alpha_{i}^{l}$ and $\delta_{i}^{l}$ are all adjustable parameters. From the universal approximation theorem, we know that we can find a fuzzy system to estimate any continuous function. For the first type of fuzzy systems, we can only adjust $\theta^{l}$ in (45). We define $f^{\wedge}(x \mid \theta)$ as the approximator of the real function $f(x)$.

$$
f^{\wedge}(x \mid \theta)=\theta^{T} \varepsilon(x)
$$

We define $\theta^{*}$ as the values for the minimum error:

$$
\theta^{*}=\arg \min _{\theta \in \Omega}\left[\sup _{x \in U}\left|f^{\wedge}(x \mid \theta)-g(x)\right|\right]
$$

Where $\Omega$ is a constraint set for $\theta$. For specific $x, \sup _{x \in U}\left|f^{\wedge}\left(x \mid \theta^{*}\right)-f(x)\right|$ is the minimum approximation error we can get.

We used the first type of fuzzy systems (44) to estimate the nonlinear system (12) the fuzzy formulation can be write as below;

$$
\begin{aligned}
f(x \mid \theta) & =\theta^{T} \varepsilon(x) \\
& =\frac{\sum_{l=1}^{n} \theta^{l}\left[\mu_{A^{l}}(x)\right]}{\sum_{l=1}^{n}\left[\mu_{A}(x)\right]}
\end{aligned}
$$

Where $\theta^{1}, \ldots, \theta^{n}$ are adjusted by an adaptation law. The adaptation law is designed to minimize the parameter errors of $\theta-\theta^{*}$. The SISO fu zzy system is define as

$$
f(x)=\ominus^{T} \varepsilon(x)
$$

Where

$$
\ominus^{T}=\left(\theta_{1}, \ldots, \theta_{m}\right)^{T}=\left[\begin{array}{c}
\theta_{1}^{1}, \theta_{1}^{2}, \ldots, \theta_{1}^{M} \\
\theta_{2}^{1}, \theta_{2}^{2}, \ldots, \theta_{2}^{M} \\
\vdots \\
\theta_{m}^{1}, \theta_{m}^{2}, \ldots, \theta_{m}^{M}
\end{array}\right]
$$

$$
\varepsilon(x)=\left(\varepsilon^{1}(x), \ldots, \varepsilon^{M}(x)\right)^{T}, \quad \varepsilon^{1}(x)=\prod_{i=1}^{n} \mu_{A_{i}^{l}}\left(x_{i}\right) /
$$

$\sum_{l=1}^{M}\left(\prod_{i=1}^{n} \mu_{A_{i}^{l}}\left(x_{i}\right)\right)$, and $\mu_{A_{i}^{l}}\left(x_{i}\right)$ is defined in (48). To reduce the number of fuzzy rules, we divide the fuzzy systemin to three parts:

$$
\begin{aligned}
F^{1}(q, \dot{q}) & =\ominus^{1^{T}} \varepsilon(q, \dot{q}) \\
& =\left[\theta_{1}^{1^{T}} \varepsilon(q, \dot{q}), \ldots, \theta_{m}^{1^{T}} \varepsilon(q, \dot{q})\right]^{T}
\end{aligned}
$$

$$
\begin{aligned}
& F^{2}\left(q, \ddot{q}_{r}\right)=\ominus^{2^{T}} \varepsilon\left(q, \ddot{q}_{r}\right) \\
& =\left[\theta_{1}^{2^{T}} \varepsilon\left(q, \ddot{q}_{r}\right), \ldots, \theta_{m}^{2^{T}} \varepsilon\left(q, \ddot{q}_{r}\right)\right]^{T} \\
& F^{3}(q, \ddot{q})=\ominus^{3^{T}} \varepsilon(q, \ddot{q}) \\
& =\left[\theta_{1}^{3^{T}} \varepsilon(q, \dot{q}), \ldots, \theta_{m}^{3^{T}} \varepsilon(q, \ddot{q})\right]^{T}
\end{aligned}
$$

The control security input is given by

$$
\begin{aligned}
& \tau=M \ddot{q}_{r}+B(q) \dot{q} \dot{q}+C(q) \dot{q}^{2}+ \\
& g(q)+F^{1}(q, \dot{q})+F^{2}\left(q, \ddot{q}_{r}\right)+F^{3}(q, \ddot{q})- \\
& K_{p} e-K_{v} \dot{e}
\end{aligned}
$$

Where $M^{\wedge}, \quad \boldsymbol{B}(\boldsymbol{q}) \dot{\boldsymbol{q}} \dot{\boldsymbol{q}}, \boldsymbol{C}(\boldsymbol{q}) \dot{\boldsymbol{q}}^{2}, \boldsymbol{g}(\boldsymbol{q})$ are the estimations of $M(q)$.

Based on sliding mode formulation (28) and PD linear methodology (5);

$$
S_{N e w}=(\dot{e}+\lambda e)
$$

And $U_{\text {switch }}$ is obtained by

$$
\begin{aligned}
& \mathrm{U}_{\text {switch }}=\mathrm{K}(\overrightarrow{\mathrm{x}}, \mathrm{t}) \cdot \operatorname{sgn}\left(\mathrm{S}_{\mathrm{New}}\right)=\mathrm{K}(\overrightarrow{\mathrm{x}}, \mathrm{t}) \cdot \\
& \operatorname{sgn}(K(\dot{e}+\lambda e))
\end{aligned}
$$

The Lyapunov function in this design is defined as

$$
V=\frac{1}{2} S^{T} M S+\frac{1}{2} \sum_{J=1}^{M} \frac{1}{\gamma_{s j}} \phi^{T} . \phi_{j}
$$

where $\gamma_{s j}$ is a positive coefficient, $\boldsymbol{\phi}=\boldsymbol{\theta}^{*}-\boldsymbol{\theta}, \boldsymbol{\theta}^{*}$ is minimum error and $\theta$ is adjustable parameter. Since $\dot{M}-2 V$ is skew-symetric matrix;

$$
S^{T} M \dot{S}+\frac{1}{2} S^{T} \dot{M} S=S^{T}(M \dot{S}+V S)
$$

If the dynamic formulation of robot manipulator defined by

$$
\tau=M(q) \ddot{q}+V(q, \dot{q}) \dot{q}+G(q)
$$

the controller formulation is defined by

$$
\tau=\widehat{M} \ddot{q}_{r}+\widehat{V} \dot{q}_{r}+\widehat{G}-\lambda S-K
$$

According to (58) and (59)

$$
\begin{aligned}
& M(q) \ddot{q}+V(q, \dot{q}) \dot{q}+G(q)=\widehat{M} \ddot{q}_{r}+\widehat{V} \dot{q}_{r}+ \\
& \hat{G}-\lambda S-K
\end{aligned}
$$

Since $\dot{\boldsymbol{q}}_{r}=\dot{\boldsymbol{q}}-\boldsymbol{S}$ and $\ddot{\boldsymbol{q}}_{r}=\ddot{\boldsymbol{q}}-\dot{\boldsymbol{S}}$

$$
M \dot{S}+(V+\lambda) S=\Delta f-K
$$

$$
M \dot{S}=\Delta f-K-V S-\lambda S
$$


The derivation of $\mathrm{V}$ is defined

$$
\begin{gathered}
\dot{V}=S^{T} M \dot{S}+\frac{1}{2} S^{T} \dot{M} S+\sum_{J=1}^{M} \frac{1}{\gamma_{s j}} \phi^{T} \cdot \dot{\phi}_{j} \\
\dot{V}=S^{T}(M \dot{S}+V S)+\sum_{J=1}^{M} \frac{1}{\gamma_{s j}} \phi^{T} \cdot \dot{\phi}_{j}
\end{gathered}
$$

Based on (61) and (62)

$$
\begin{aligned}
& \dot{\mathrm{V}}=\mathrm{S}^{\mathrm{T}}(\Delta \mathrm{f}-\mathrm{K}-\mathrm{VS}-\lambda \mathrm{S}+\mathrm{VS})+ \\
& \sum_{\mathrm{J}=1}^{\mathrm{M}} \frac{1}{\gamma_{\mathrm{sj}}} \phi^{\mathrm{T}} \cdot \dot{\phi}_{\mathrm{j}}
\end{aligned}
$$

where $\sum_{l=1}^{M} \theta^{T} \zeta(x)$

$$
\dot{V}=\sum_{J=1}^{M}\left[S_{j}\left(\Delta f_{j}-K_{j}\right)\right]-S^{T} \lambda S+\sum_{J=1}^{M} \frac{1}{\gamma_{s j}} \phi^{T} \cdot \dot{\phi}_{j}
$$

suppose $K_{j}$ is defined as follows

$$
K_{j}=\frac{\sum_{l=1}^{M} \theta_{j}^{l}\left[\mu_{A}\left(S_{j}\right)\right]}{\sum_{l=1}^{M}\left[\mu_{A}\left(S_{j}\right)\right]}=\theta_{j}^{T} \zeta_{j}\left(S_{j}\right)
$$

Where

$$
\begin{gathered}
\zeta_{j}\left(S_{j}\right)=\left[\zeta_{j}^{1}\left(S_{j}\right), \zeta_{j}^{2}\left(S_{j}\right), \zeta_{j}^{3}\left(S_{j}\right), \ldots ., \zeta_{j}^{M}\left(S_{j}\right)\right]^{T} \\
\zeta_{j}^{1}\left(S_{j}\right)=\frac{\mu_{(A)}^{l}{ }_{j}^{l}\left(S_{j}\right)}{\sum_{i} \mu_{(A)}{ }_{j}^{l}\left(S_{j}\right)}
\end{gathered}
$$

where $\mu_{(x i)}$ is membership function.

The fuzzy systemis defined as

$$
f(x)=\tau_{f u z z y}=\sum_{l=1}^{M} \theta^{T} \zeta(x)=\psi(e, \dot{e})
$$

where $\theta=\left(\theta^{1}, \theta^{2}, \theta^{3}, \ldots \ldots, \theta^{M}\right)$ is adjustable parameter in (65) according to (62), (63) and (65);

$$
\begin{aligned}
& \dot{V}=\sum_{J=1}^{M}\left[S_{j}\left(\Delta f_{\mathrm{j}}-\theta^{T} \zeta\left(S_{j}\right)\right]-S^{T} \lambda S+\right. \\
& \sum_{J=1}^{M} \frac{1}{\gamma_{s j}} \phi^{T} \cdot \dot{\phi}_{j}
\end{aligned}
$$

Based on $\boldsymbol{\phi}=\boldsymbol{\theta}^{*}-\boldsymbol{\theta} \rightarrow \boldsymbol{\theta}=\boldsymbol{\theta}^{*}-\boldsymbol{\phi}$

$$
\begin{aligned}
& \dot{\mathrm{V}}= \\
& \sum_{\mathrm{J}=1}^{\mathrm{M}}\left[\mathrm{S}_{\mathrm{j}}\left(\Delta \mathrm{f}_{\mathrm{j}}-\theta^{* \mathrm{~T}} \zeta\left(\mathrm{S}_{\mathrm{j}}\right)+\phi^{\mathrm{T}} \zeta\left(\mathrm{S}_{\mathrm{j}}\right)\right]-\mathrm{S}^{\mathrm{T}} \lambda \mathrm{S}+\right. \\
& \sum_{\mathrm{J}=1}^{\mathrm{M}} \frac{1}{\gamma_{\mathrm{sj}}} \phi^{\mathrm{T}} \cdot \dot{\phi}_{\mathrm{j}}
\end{aligned}
$$

$$
\begin{aligned}
\dot{V}=\sum_{J=1}^{M}\left[S _ { j } \left(\Delta f_{\mathrm{j}}-\right.\right. & \left.\left(\theta^{*}\right)^{T} \zeta\left(S_{j}\right)\right]-S^{T} \lambda S \\
& \left.+\sum_{J=1}^{M} \frac{1}{\gamma_{s j}} \phi_{j}^{T}\left[\gamma_{s j} \cdot S_{j} \cdot \zeta_{j}\left(S_{j}\right)+\dot{\phi}_{j}\right]\right)
\end{aligned}
$$

where $\dot{\boldsymbol{\theta}}_{\boldsymbol{j}}=\boldsymbol{\gamma}_{\boldsymbol{s} \boldsymbol{j}} \boldsymbol{S}_{\boldsymbol{j}} \boldsymbol{\zeta}_{\boldsymbol{j}}\left(\boldsymbol{S}_{\boldsymbol{j}}\right)$ is adaption law, $\phi_{\boldsymbol{j}}=-\dot{\boldsymbol{\theta}}_{\boldsymbol{j}}=$ $-\gamma_{s j} S_{j} \zeta_{j}\left(S_{j}\right)$

$\dot{\boldsymbol{V}}$ is considered by

$$
\dot{V}=\sum_{j=1}^{m}\left[S_{j} \Delta f_{j}-\left(\left(\theta_{j}^{*}\right)^{T} \zeta_{j}\left(S_{j}\right)\right)\right]-S^{T} \lambda S
$$

The minimum error is defined by

$$
e_{m j}=\Delta f_{j}-\left(\left(\theta_{j}^{*}\right)^{T} \zeta_{j}\left(S_{j}\right)\right)
$$

Therefore $\dot{\boldsymbol{V}}$ is computed as

$$
\begin{gathered}
\dot{V}=\sum_{j=1}^{m}\left[S_{j} e_{m j}\right]-S^{T} \lambda S \\
\leq \sum_{j=1}^{m}\left|S_{j}\right|\left|e_{m j}\right|-S^{T} \lambda S \\
=\sum_{j=1}^{m}\left|S_{j}\right|\left|e_{m j}\right|-\lambda_{j} S_{j}{ }^{2} \\
=\sum_{j=1}^{m}\left|S_{j}\right|\left(\left|e_{m j}\right|-\lambda_{j} S_{j}\right)
\end{gathered}
$$

For continuous function $g(x)$, and suppose $\varepsilon>0$ it is defined the fuzzy logic system in form of

$$
\operatorname{Sup}_{x \in U}|f(x)-g(x)|<\epsilon
$$

the minimum approximation error $\left(e_{m j}\right)$ is very small.

$$
\begin{aligned}
& \text { if } \lambda_{j}=\alpha \text { that } \alpha\left|S_{j}\right|>e_{m j}\left(S_{j} \neq\right. \\
& 0) \text { then } \dot{V}<0 \text { for }\left(S_{j} \neq 0\right)
\end{aligned}
$$

This method has two main controller's coefficients, $K_{p}$ and $K_{V}$. To tune and optimize these parameters mathematical formulation is used

$$
\begin{aligned}
& U=U_{f u z z y}+U_{\text {sliding }}+U_{P D} \\
& \mathrm{U}=\mathrm{U}_{\text {fuzzy }}+\mathrm{U}_{\mathrm{sw} \text { itch }}=\left[\boldsymbol{M}^{-\mathbf{1}}(\boldsymbol{B}+\boldsymbol{C}+\right. \\
& \boldsymbol{G})+\dot{\boldsymbol{S}}] \boldsymbol{M}+\boldsymbol{K} \cdot \operatorname{sgn}(\boldsymbol{S})+ \\
& \frac{\sum_{\mathrm{l}=1}^{\mathrm{M}} \theta^{\mathrm{l}}\left[\Pi_{\mathrm{i}=1}^{\mathrm{n}} \exp \left(-\left(\frac{\mathrm{x}_{\mathrm{i}}-\alpha_{\mathrm{i}}^{\mathrm{l}}}{\delta_{\mathrm{i}}^{\mathrm{l}}}\right)^{2}\right)\right]}{\sum_{\mathrm{l}=1}^{\mathrm{M}}\left[\Pi_{\mathrm{i}=1}^{\mathrm{n}} \exp \left(-\left(\frac{\mathrm{x}_{\mathrm{i}}-\alpha_{\mathrm{i}}^{\mathrm{l}}}{\delta_{\mathrm{i}}^{\mathrm{l}}}\right)^{2}\right)\right]}+\boldsymbol{K}_{\boldsymbol{p}_{\boldsymbol{a}}} \boldsymbol{e}_{\mathbf{1}}+ \\
& \boldsymbol{K}_{\boldsymbol{V}_{\boldsymbol{a}}} \dot{\boldsymbol{e}}_{\mathbf{1}}+\boldsymbol{K}_{\boldsymbol{I} \boldsymbol{a}} \sum \boldsymbol{e}_{\mathbf{1}}
\end{aligned}
$$

The most important different between PD+SMC and $\mathrm{PD}+\mathrm{SMC}+\mathrm{FL}$ is the uncertainty. In $\mathrm{PD}+\mathrm{SMC}$ the uncertainty is $d=G+F+f$. The sliding mode gain must be bigger than its upper bound. It is not an easy job because this term includes tracking errors $e_{1}$ and $\dot{q}_{1}$. While in PD+SMC+FL, the uncertainty $\eta$ is the fuzzy approximation error for $G+F+f$. 


$$
G+F+f=\frac{\sum_{l=1}^{M} \theta^{l}\left[\prod_{i=1}^{n} \exp \left(-\left(\frac{x_{i}-\alpha_{i}^{l}}{\delta_{i}^{l}}\right)^{2}\right)\right]}{\sum_{l=1}^{M}\left[\prod_{i=1}^{n} \exp \left(-\left(\frac{x_{i}-\alpha_{i}^{l}}{\delta_{i}^{l}}\right)^{2}\right)\right]}
$$

It is usually is smaller than $G+F+f$; and the upper bound of it is easy to be estimated.

\section{Results and Discussion}

In this section, we use a benchmark model, PUMA560 robot manipulator, to evaluate our control algorithms [22]. We compare the following controllers: classical PD controller, PD fuzzy controller and serial fuzzy sliding mode PD controller which is proposed in this paper. The simulation was implemented in MATLAB/SIMULINK environment.

Close loop response of tracking result without any disturbance: Figure 2 illustrates the tracking performance in three types of controller; linear PD controller, linear PD controller based on fuzzy logic estimator and nonlinear estimator based on fuzzy logic and sliding mode controller.
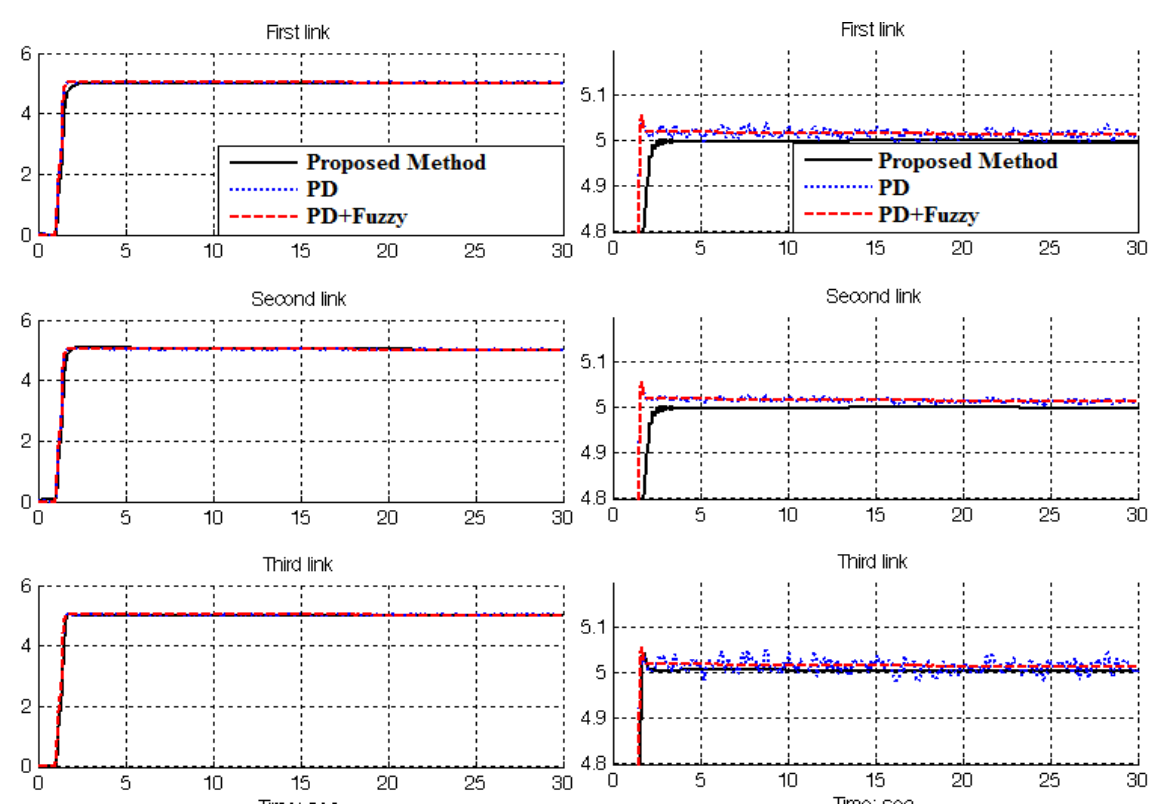

Fig. 2: Linear PD, PD+FLC and Proposed method trajectory following without disturbance
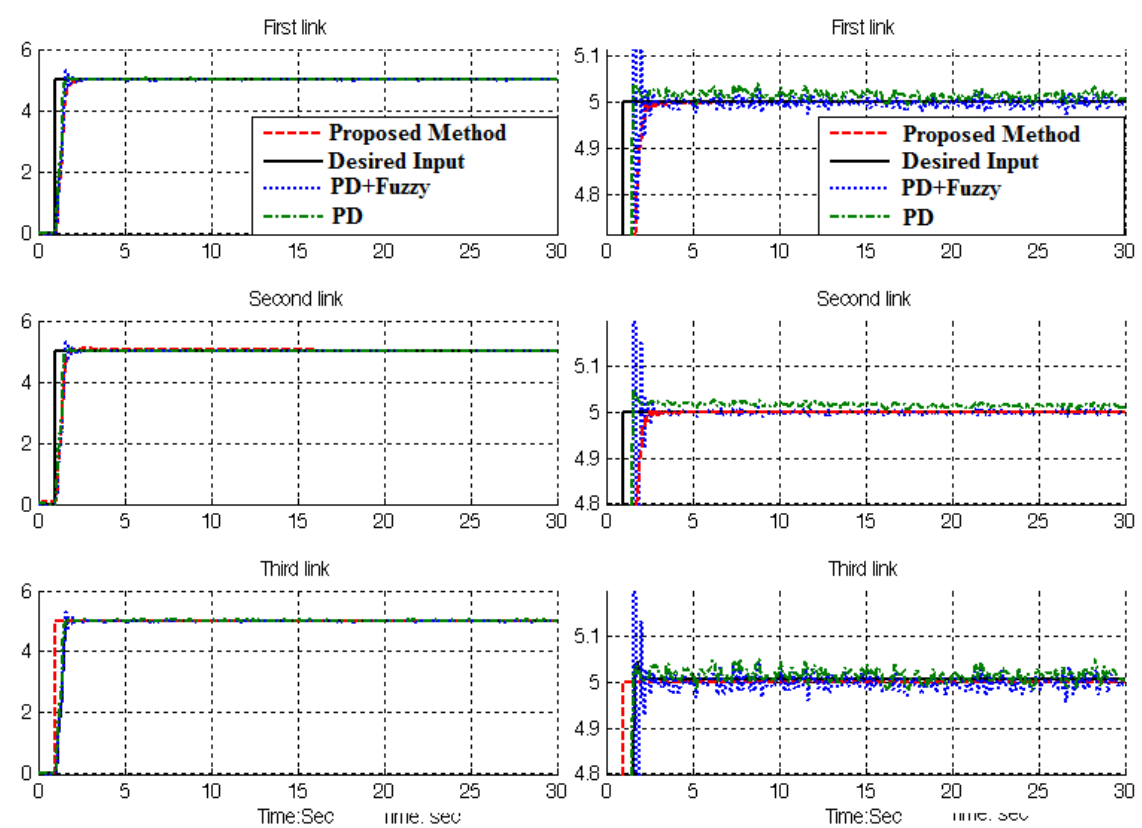

Fig. 3: Linear PD, PD+FLC and Proposed method trajectory following with disturbance 
Based on Figure 2; pure PD controller has oscillation in first and three links, because robot manipulator is a highly nonlinear controller and control of this system by linear method is very difficult. Based on above graph, however PD+FUZZY controller is a nonlinear methodology but it has difficulty to control this plant because it is a model base controller.

Close loop response of trajectory following in presence of load disturbance: Figure 3 demonstrates the power disturbance elimination in three types of controller in presence of disturbance for robot manipulator. The disturbance rejection is used to test the robustness comparisons of these three methodologies.

Based on Figure 3; by comparison with the PD and PD+FLC, proposed serial compensator $\mathrm{PD}+\mathrm{Fuzzy}+\mathrm{SMC}$ is more stable and robust and our method doesn't have any chattering and oscillation.

\section{Conclusion}

The main contributions of the paper are twofold. The structure of fuzzy PD control with sliding mode compensation is new. We propose parallel structure: parallel compensation. The key technique is dead-zone, such that fuzzy control and sliding mode control can be switched automatically. The stability analysis of fuzzy sliding mode PD control is also new. Stability analys is of fuzzy PD control with first-order or second-order sliding mode is not published in the literature. The benefits of the proposed method; the chattering effects of fuzzy slid ing mode PD control, the slow convergence of the fuzzy PD and the chattering problem of sliding mode PD control are avoided effectively.

\section{Acknowledgment}

The authors would like to thank the anonymous reviewers for their careful reading of this paper and for their helpful comments. This work was supported by the SSP Research and Development Corporation Program of Iran under grant no. 2012-Persian Gulf-3C.

\section{References}

[1] T. R. Kurfess, Robotics and automation handbook: CRC, 2005.

[2] J. J. E. Slotine and W. Li, Applied nonlinear control vol. 461: Prentice hall Englewood Cliffs, NJ, 1991.

[3] K. Ogata, Modern control engineering: Prentice Hall, 2009.
[4] J. J. D'Azzo, C. H. Houpis and S. N. Sheldon, Linear control system analysis and design with MATLAB: CRC, 2003.

[5] B. Siciliano and O. Khatib, Springer handbook of robotics: Springer-Verlag New York Inc, 2008.

[6] F. T. Cheng, T. L. Hour, Y. Y. Sun and T. H. Chen, "Study and resolution of singularities for a 6-DOF PUMA manipulator," Systems, Man, and Cybernetics, Part B: Cybernetics, IEEE Transactions on, No. 2, vol. 27, pp. 332-343, 2002.

[7] M. W. Spong and M. Vidyasagar, Robot dynamics and control: Wiley-India, 2009.

[8] A. Vivas and V. Mosquera, "Predictive functional control of a PUMA robot," Conference Proceedings, 2005.

[9] D. Nguyen-Tuong, M. Seeger and J. Peters, "Computed torque control with nonparametric regression models," IEEE conference proceeding, 2008, pp. 212-217.

[10] Farzin Piltan , N. Sulaiman, Zahra Tajpaykar, Payman Ferdosali, Mehdi Rashidi, "Design Artificial Nonlinear Robust Controller Based on CTLC and FSMC with Tunable Gain," International Journal of Robotic and Automation, 2 (3): 205-220, 2011.

[11] Farzin Piltan, A. R. Salehi and Nasri B Sulaiman.," Design artificial robust control of second order system based on adaptive fuzzy gain scheduling," world applied science journal (WASJ), 13 (5): 1085-1092, 2011.

[12] Farzin Piltan, N. Sulaiman, Atefeh Gavahian, Samira Soltani, Samaneh Roosta, "Design Mathematical Tunable Ga in PID-Like Sliding Mode Fuzzy Controller with Minimum Rule Base," International Journal of Robotic and Automation, 2 (3): 146-156, 2011.

[13] Farzin Piltan, A. Zare, Nasri B. Sulaiman, M. H. Marhaban and R. Ramli, , "A Model Free Robust Sliding Surface Slope Adjustment in Sliding Mode Control for Robot Manipulator," World Applied Science Journal, 12 (12): 2330-2336, 2011.

[14] Farzin Piltan, A. H. Aryanfar, Nasri B. Sulaiman, M. H. Marhaban and R. Ramli "Design Adaptive Fuzzy Robust Controllers for Robot Manipulator," World Applied Science Journal, 12 (12): 2317 2329, 2011.

[15] Farzin Piltan, N. Sulaiman , Arash Zargari, Mohammad Keshavarz, Ali Badri, "Design PIDLike Fuzzy Controller With Minimum Rule Base and Mathematical Proposed On-line Tunable Gain: Applied to Robot Manipulator," International Journal of Artificial intelligence and expert system, 2 (4):184-195, 2011. 
[16] Farzin Piltan, Nasri Sulaiman, M. H. Marhaban and R. Ramli, "Design On-Line Tunable Gain Artificial Nonlinear Controller," Journal of Advances In Computer Research, 2 (4): 75-83, 2011.

[17] Farzin Piltan, N. Su laiman, Pay man Ferdosali, Iraj Assadi Talooki, “ Design Model Free Fuzzy Sliding Mode Control: Applied to Internal Combustion Engine," International Journal of Engineering, 5 (4):302-312, 2011.

[18] Farzin Piltan, N. Sulaiman, Samaneh Roosta, M.H. Marhaban, R. Ramli, "Design a New Slid ing Mode Adaptive Hybrid Fuzzy Controller," Journal of Advanced Science \& Engineering Research , 1 (1): 115-123, 2011.

[19] Farzin Piltan, Atefe Gavahian, N. Sulaiman, M.H. Marhaban, R. Ramli, "Novel Sliding Mode Controller for robot manipulator using FPGA," Journal of Advanced Science \& Engineering Research, 1 (1): 1-22, 2011.

[20] Farzin Piltan, N. Sulaiman, A. Jalali \& F. Danesh Narouei, "Design of Model Free Adaptive Fuzzy Computed Torque Controller: Applied to Nonlinear Second Order System," International Journal of Robotics and Automation, 2 (4):232-244, 2011.

[21] Farzin Piltan, N. Sulaiman, Iraj Asadi Talooki, Payman Ferdosali, "Control of IC Engine: Design a Novel MIMO Fuzzy Backstepping Adaptive Based Fuzzy Estimator Variable Structure Control ," International Journal of Robotics and Automation, 2 (5):360-380, 2011.

[22] Farzin Piltan, N. Sulaiman, Payman Ferdosali, Mehdi Rashidi, Zahra Tajpeikar, "Adaptive MIMO Fuzzy Compensate Fuzzy Sliding Mode Algorith m: Applied to Second Order Nonlinear System," International Journal of Engineering, 5 (5): 380 398, 2011.

[23] Farzin Piltan, N. Sulaiman, Hajar Nasiri, Sadeq Allahdadi, Mohammad A. Bairami, "Novel Robot Manipulator Adaptive Artificial Control: Design a Novel SISO Adaptive Fuzzy Sliding Algorithm Inverse Dynamic Like Method," International Journal of Engineering, 5 (5): 399-418, 2011.

[24] Samira Soltani \& Farzin Piltan, "Design Artificial Nonlinear Controller Based on Computed Torque like Controller with Tunable Gain". World Applied Science Journal,14 (9): 1306-1312, 2011.

[25] Farzin Piltan, N. Sulaiman, Sadeq Allahdadi, Mohammadali Dialame, Abbas Zare, "Position Control of Robot Manipulator: Design a Novel SISO Adaptive Sliding Mode Fuzzy PD Fuzzy Sliding Mode Control," International Journal of Artificial intelligence and Expert System, 2 (5):208-228, 2011.
[26] Farzin Piltan, SH. Tayebi HAGHIGHI, N. Sulaiman, Iman Nazari, Sobhan Siamak, "Artificial Control of PUMA Robot Manipulator: A-Review of Fuzzy Inference Engine And Application to Classical Controller ,' International Journal of Robotics and Automation, 2 (5):401-425, 2011.

[27] Farzin Piltan, N. Sulaiman, Abbas Zare, Sadeq Allahdadi, Mohammadali Dialame, "Design Adaptive Fuzzy Inference Sliding Mode Algorith m: Applied to Robot Arm," International Journal of Robotics and Automation , 2 (5): 283-297, 2011.

[28] Farzin Piltan, Amin Jalali, N. Sulaiman, Atefeh Gavahian, Sobhan Siamak, "Novel Artificial Control of Nonlinear Uncertain System: Design a Novel Modified PSO SISO Lyapunov Based Fuzzy Sliding Mode Algorithm ," International Journal of Robotics and Automation, 2 (5): 298 316, 2011.

[29] Farzin Piltan, N. Sulaiman, Amin Jalali, Koorosh Aslansefat, "Evolutionary Design of Mathematical tunable FPGA Based MIMO Fuzzy Estimator Sliding Mode Based Lyapunov Algorithm: Applied to Robot Manipulator," International Journal of Robotics and Automation, 2 (5):317-343, 2011.

[30] Farzin Piltan, N. Sulaiman, Samaneh Roosta, Atefeh Gavahian, Samira Soltani, "Evolutionary Design of Backstepping Artificial Sliding Mode Based Position Algorithm: Applied to Robot Manipulator," International Journal of Engineering, 5 (5):419-434, 2011.

[31] Farzin Piltan, N. Sulaiman, S.Soltani, M. H. Marhaban \& R. Ramli, "An Adaptive sliding surface slope adjustment in PD Sliding Mode Fuzzy Control for Robot Manipulator," International Journal of Control and Automation , 4 (3): 65-76, 2011.

[32] Farzin Piltan, N. Sulaiman, Mehdi Rashidi, Zahra Tajpaikar, Payman Ferdosali, "Design and Implementation of Sliding Mode Algorithm: Applied to Robot Manipulator-A Review ," International Journal of Robotics and Automation, 2 (5):265-282, 2011.

[33] Farzin Piltan, N. Sulaiman, Amin Jalali, Sobhan Siamak, and Iman Nazari, "Control of Robot Manipulator: Design a Novel Tuning MIMO Fuzzy Backstepping Adaptive Based Fuzzy Estimator Variable Structure Control ," International Journal of Control and Automation, 4 (4):91-110, 2011.

[34] Farzin Piltan, N. Sulaiman, Atefeh Gavahian, Samaneh Roosta, Samira Soltani, "On line Tuning Premise and Consequence FIS: Design Fuzzy Adaptive Fuzzy Sliding Mode Controller Based on 
Lyaponuv Theory," International Journal of Robotics and Automation, 2 (5):381-400, 2011.

[35] Farzin Piltan, N. Sulaiman, Samaneh Roosta, Atefeh Gavahian, Samira Soltani, "Artificial Chattering Free on-line Fuzzy Sliding Mode Algorithm for Uncertain System: Applied in Robot Manipulator," International Journal of Engineering, 5 (5):360-379, 2011.

[36] Farzin Piltan, N. Sulaiman and I.AsadiTalooki, "Evolutionary Design on-line Sliding Fuzzy Gain Scheduling Sliding Mode Algorithm: Applied to Internal Co mbustion Engine," International Journal of Engineering Science and Technology, 3 (10):7301-7308, 2011

[37] Farzin Piltan, Nasri B Su laiman, Iraj Asadi Talooki and Payman Ferdosali.," Designing On-Line Tunable Gain Fuzzy Sliding Mode Controller Using Sliding Mode Fuzzy Algorithm: Applied to Internal Combustion Engine," world applied science journal (WASJ), 15 (3): 422-428, 2011.

[38] B. K. Yoo and W. C. Ham, "Adaptive control of robot manipulator using fuzzy compensator," Fuzzy Systems, IEEE Transactions on, No. 2, vol. 8, pp. 186-199, 2002.

[39] Y. S. Kung, C. S. Chen and G. S. Shu, "Design and Implementation of a Servo System for Robotic Manipulator," CACS, 2005.

[40] Farzin Piltan, N. Sulaiman, M. H. Marhaban, Adel Nowzary, Mostafa Tohidian," "Design of FPGA based sliding mode controller for robot manipulator," International Journal of Robotic and Automation, 2 (3): 183-204, 2011.

[41] Farzin Piltan, M. Mirzaie, F. Shahriyari, Iman Nazari \& S. Emamzadeh." Design Baseline Computed Torque Controller" International Journal of Engineering, 3(3): 2012.

[42] Farzin Piltan, H. Rezaie, B. Boroomand, Arman Jahed," Design robust back stepping online tuning feedback linearization control applied to IC engine," International Journal of Advance Science and Technology, 42: 183-204, 2012.

[43] Farzin Piltan, I. Nazari, S. Siamak, P. Ferdosali ,'Methodology of FPGA-based mathematical error-based tuning sliding mode controller" International Journal of Control and Automation, 5(1): 89-110, 2012.

[44] Farzin Piltan, M. A. Dialame, A. Zare, A. Badri ,'Design Novel Lookup table changed Auto Tuning FSMC: Applied to Robot Manipulator" International Journal of Engineering, 6(1): 25-40, 2012.

[45] Farzin Piltan, B. Boroomand, A. Jahed, H. Rezaie ,"Methodology of Mathematical ErrorBased Tuning Sliding Mode Controller'
International Journal of Engineering, 6(2): 96-112, 2012.

[46] Farzin Piltan, F. Aghayari, M. R. Rashidian, M. Shamsodini, "A New Estimate Sliding Mode Fuzzy Controller for Robotic Manipulator" International Journal of Robotics and Automation, 3(1): 45-58, 2012.

[47] Farzin Piltan, M. Keshavarz, A. Badri, A. Zargari,"Design novel nonlinear controller applied to robot manipulator: design new feedback linearization fuzzy controller with minimum rule base tuning method" International Journal of Robotics and Automation, 3(1): 1-18, 2012.

[48] Piltan, F., et al. "Design sliding mode controller for robot manipulator with artificial tunable gain". Canaidian Journal of pure and applied science, 5 (2), 1573-1579, 2011.

[49] Farzin Piltan, A. Hosainpour, E. Mazlomian, M.Shamsodini, M.H Yarmahmoudi. "Online Tuning Chattering Free Sliding Mode Fuzzy Control Design: Lyapunov Approach" International Journal of Robotics and Automation, 3(3): 2012.

[50] Farzin Piltan , M.H. Yarmah moudi, M. Shamsodini, E.Mazlo mian, A.Hosainpour. " PUMA-560 Robot Manipulator Position Computed Torque Control Methods Using MATLAB/SIMULINK and Their Integration into Graduate Nonlinear Control and MATLAB Courses" International Journal of Robotics and Automation, 3(3): 2012.

[51] Farzin Piltan, R. Bayat, F. Aghayari, B. Boroomand. "Design Error-Based Linear ModelFree Evaluation Performance Computed Torque Controller" International Journal of Robotics and Automation, 3(3): 2012.

[52] Farzin Piltan, S. Emamzadeh, Z. Hivand, F. Shahriyari \& Mina Mirazaei ." PUMA-560 Robot Manipulator Position Sliding Mode Control Methods Using MATLAB/SIMULINK and Their Integration into Graduate/Undergraduate Nonlinear Control, Robotics and MATLAB Courses" International Journal of Robotics and Automation, 3(3): 2012.

[53] Farzin Piltan, J. Meigolinedjad, S. Mehrara, S. Rahmdel. "Evaluation Performance of 2nd Order Nonlinear System: Baseline Control Tunable Gain Sliding Mode Methodology" International Journal of Robotics and Automation, 3(3): 2012.

[54] Farzin Piltan, S. Siamak, M.A. Bairami and I. Nazari. "Gradient Descent Optimal Chattering Free Sliding Mode Fuzzy Control Design: Lyapunov Approach" International Journal of Advanced Science and Technology, 43: 2012.

[55] Farzin Piltan, M.R. Rashidian, M. Shamsodini and S. Allahdadi." Effect of Rule Base on the Fuzzy- 
Based Tuning Fuzzy Sliding Mode Controller: Applied to 2nd Order Nonlinear System" International Journal of Advanced Science and Technology, 46:2012.

[56] Farzin Piltan, A. Jahed, H. Rezaie and B. Boroomand." Methodology of Robust Linear Online High Speed Tuning for Stable Sliding Mode Controller: Applied to Nonlinear System" International Journal of Control and Automation, 5(3): 2012.

[57] Farzin Piltan, R. Bayat, S. Mehara and J. Meigolinedjad. "GDO Artificial IntelligenceBased Switching PID Baseline Feedback Linearization Method: Controlled PUMA Workspace" International Journal of Information Engineering and Electronic Business, 2012.

[58] Farzin Piltan, B. Boroomand, A. Jahed and H. Rezaie. "Performance-Based Adaptive Gradient Descent Optimal Coefficient Fuzzy Sliding Mode Methodology" International Journal of Intelligent Systems and Applications, 2012.

[59] Farzin Piltan, S. Mehrara, R. Bayat and S. Rahmdel. " Design New Control Methodology of Industrial Robot Manipulator: Sliding Mode Baseline Methodology" International Journal of Hybrid Information Technology, 5(4): 2012.

[60] Farzin Piltan, M. Akbari, M. Piran, M. Bazregar. "Design Model Free Switching Gain Scheduling Baseline Controller with Application to Automotive Engine" International Journal of Information Technology and Computer Science, 2013.

\section{Authors' Profiles}

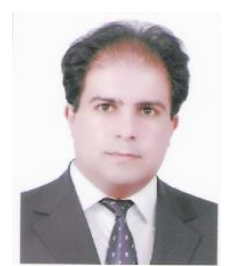

Farzin Piltan was born on 1975, Shiraz, Iran. In 2004 he is jointed the research and development company, SSP Co, Shiraz, Iran. In addition to 7 textbooks, Farzin Piltan is the main author of more than 62 scientific papers in refereed journals. $\mathrm{He}$ is editorial board of international journal of control and automation (IJCA), editorial board of International Journal of Intelligent System and Applications (IJISA), editorial board of IAES international journal of robotics and automation, editorial board of International Journal of Reconfigurable and Embedded Systems and reviewer of (CSC) international journal of robotics and automation. His main areas of research interests are nonlinear control, artificial control system and applied to FPGA, robotics and artificial nonlinear control and IC engine modelling and control.

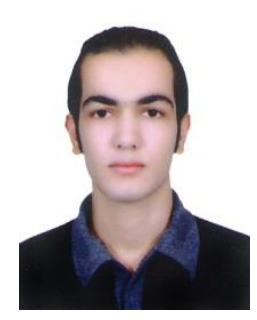

Mohammad A. Bairami is a
computer researcher of research and
development company SSP. Co. He
is an expert artificial intelligence and
computer engineer in this company.
His research activities deal with the
robotic control, artificial intelligence
and expert system.

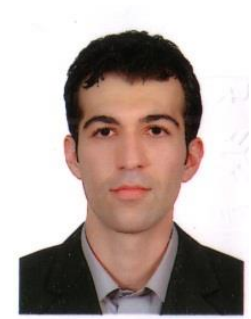

Farid Aghayari is an electrical researcher of research and development company SSP. Co. His main areas of research interests are nonlinear control and artificial control system.

Mohammad. R Rashidian is an electrical engineer researcher of research and development company SSP. $\mathrm{Co}$. He is an expert electrical control engineer in this company. His research activities deal with the robotic control, artificial intelligence and expert system.

How to cite this paper: Farzin Piltan, Mohammad A. Bairami, Farid Aghayari, Mohammad Reza Rashidian,"Stable Fuzzy PD Control with Parallel Sliding Mode Compensation with Application to Rigid Manipulator", International Journal of Information Technology and Computer Science(IJITCS), vol.5, no.7, pp.103-114, 2013. DOI: 10.5815/ijitcs.2013.07.12 